\author{
Eligiusz Mieloszyk \\ prof. dr hab. inż. \\ Politechnika Gdańska \\ Wydział Inżynierii Lądowej i Środowiska \\ emieloszyk@mif.pg.gda.pl

\section{Sławomir Grulkowski} \\ dr inż. \\ Politechnika Gdańska \\ Wydział Inżynierii Lądowej i Środowiska \\ slawi@pg.edu.pl
}

DOI: 10.35117/A_ENG_17_09_04

\title{
Analog modelling in qualitative analysis of vibration propagation
}

\begin{abstract}
The theory of dynamic systems is usually used to model the real systems. The models are based on solving ordinary differential equations, partial or difference, which enable obtaining the relation between input signal and the system response (output signal). The analogy between those models and generalized dynamic systems or control systems can be practically used. Vibration propagation can be described in a similar way as the phenomena of vibrations of the electrical, mechanical, or hydraulic systems, diffusion, heat propagation, wave propagation or advection. The physical problem will be solved based on generalized dynamic systems, which enables drawing corresponding conclusions. This concept will be applied to qualitative analysis of vibration propagation in the foundations of transportation constructions".
\end{abstract}

Keywords: Analog modeling; Vibrations; Vibration propagation; Construction stability

\section{Introduction}

In general, we can divide the vibrations into generated ones:

- deliberately (with a relatively short duration),

- unintentionally (with longer or long durations).

The first of the characteristic parameters are generated within the active experiments. They can be generated using the inductor stimulated by a high-frequency impulse, elastic vibrations (elastic waves) recorded using, for example, fiber optic sensors, which are, importantly, insensitive to the influence of the electromagnetic field. They can also be used to measure other physical parameters such as deformation, temperature, pressure, etc., and thus to study various types of structures: buildings, bridges, pipelines, as well as vehicles (locomotives, wagons, ships, planes) or their elements [7].

FBG sensors are the most commonly used, the operating principle of which is presented in Fig. 1. They are in fact spectral filters that use the Bragg reflection principle and are used to detect and locate damage. Changes in the wavelength after propagation through the damaged area or after reflection from the damage can be detected by the decoder, which uses barrier filters (shut-off), adjustable narrowband filters. 

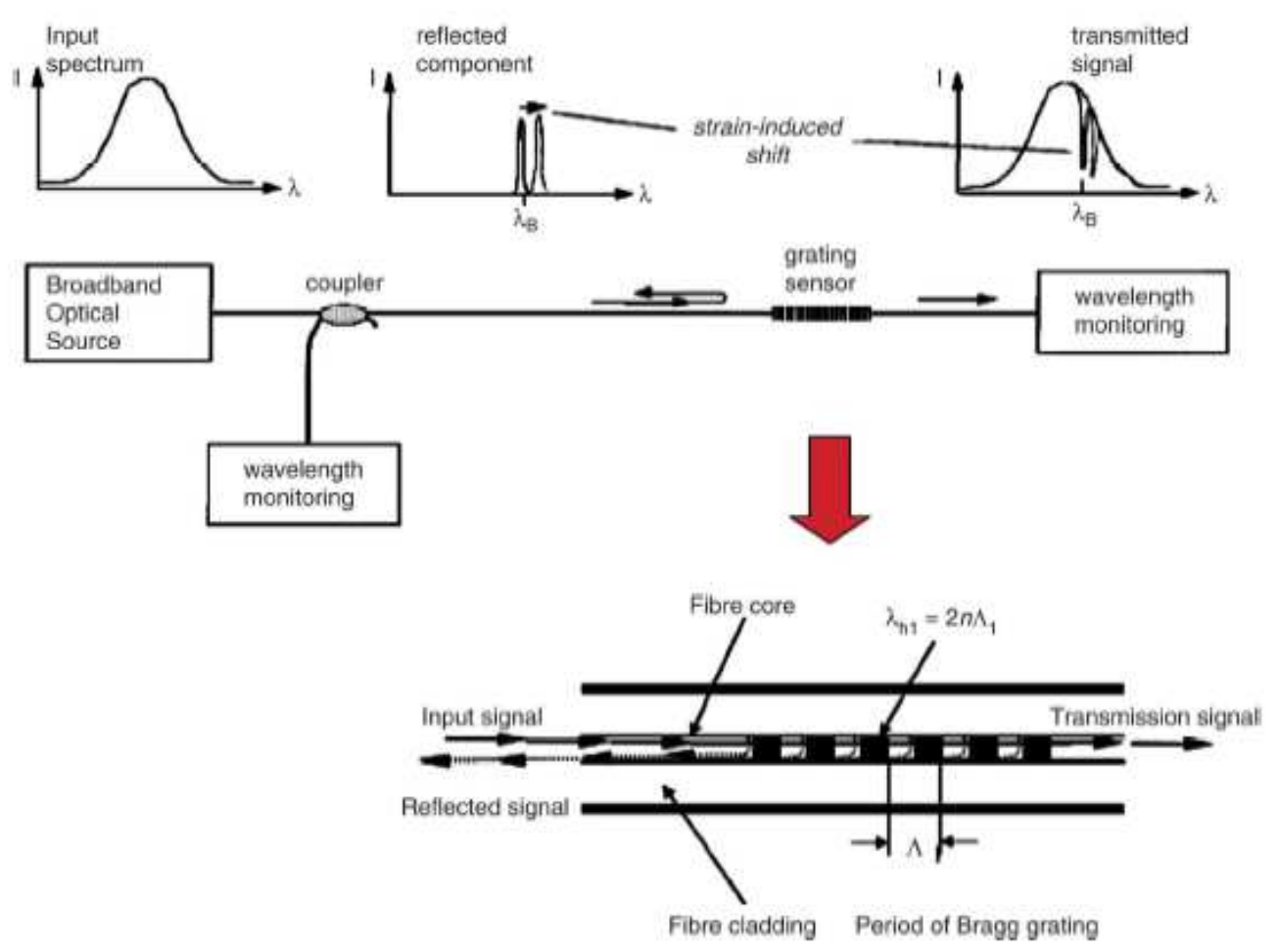

1. Principle of the FBG sensor [2]

According to a similar principle, a subsoil for transport investments (roads, tunnels) is examined in order to determine the layout of geological layers. In this case, the vibrations are excited by special vibrating vehicles (with vibrating plates) producing vibrations of $8-90 \mathrm{~Hz}$ for $10-16 \mathrm{~s}$ repeated at a given point for about $5 \mathrm{~min}$. (periodic oscillations). Reflected vibrations from individual layers are recorded by geophones, according to an analogous principle as in Fig. 1.

The latter are generally undesirable, they are a side effect of other activities (processes) and have a negative impact on people and the environment. They are measured and used in a passive experiment in order to register them, and then to eliminate vibration eliminators (Fig. 2), mechanical vibration filters and reduce their negative effects on humans and the environment. They are also used to monitor the technical condition of the structure during its current operation (during the movement of the train, the movement of transport vessels exposed to long-term cyclical loads of high values caused by the continuous operation of waves, aircraft movements, etc.).

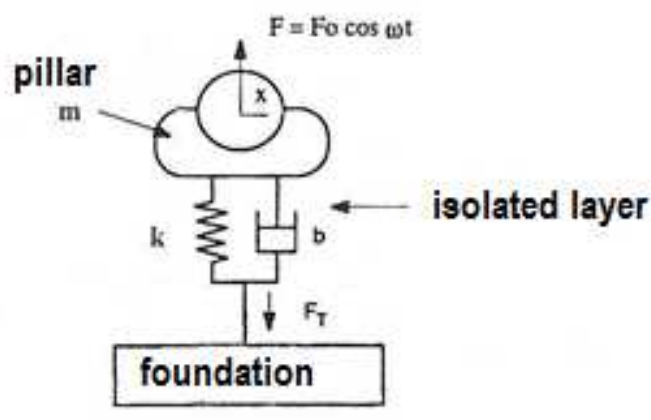

2. Elimination of vibrations using a vibration isolating layer [10] 


\section{Analytical determinants of the issue}

In engineering practice, similar phenomena leading to analog modeling are of great importance. Without the concept of similar phenomena, each phenomenon should be investigated separately, while knowing the similarity of phenomena one can use individual research results to determine the characteristics of new devices or processes. It gives the possibility to draw conclusions based on the operation of one device as to the behavior of the other device or the behavior of a given process. This is also the case in creating generalized dynamic systems [9], which due to their generality include continuous and discrete systems of their scope, with concentrated and distributed parameters, stationary and non-stationary, and which are often modeled using ordinary, partial differential equations, equations differentials, or their configurations. One of the goals of these activities is to look for a connection between the input and output signal, i.e. the response of the system. Only the adoption of a specific representation of the system leads to a detailed analysis of a specific problem and phenomenon, it allows to establish certain relationships between elements of a given system, and indicate the directions of the process leading to its improvement, its more efficient to achieve the expected results, or improve the reliability of the system as whole or part of it.

We know perfectly well that instead of analyzing electrical systems $R, L, C$ (resistance, self-induction, capacitance) under the influence of electromotive force $E$, we can consider mechanical systems consisting of mass $m$, spring with coefficient of stiffness (elasticity) $k$ and friction resistance $r$ (damping) ) under the influence of external force $F$. This is possible because of the following relationship

$$
\mathrm{k} \leftrightarrow \frac{1}{C} \quad \mathrm{r} \leftrightarrow \mathrm{R} \quad \mathrm{m} \leftrightarrow \mathrm{L}
$$

mechanical and electrical models are described by the same ordinary differential equations, that is, the same from the formal point of view of dynamic systems [12]. These are known ordinary differential equations of the second order [14]. The same applies to the corresponding hydraulic systems. They are so-called analog models. This approach allows, for example, to model mechanical vibrations or water flow through currents $I$ in a suitable electrical system and vice versa. These are typical vibrating systems and are also used for modeling (constructing) vibroisolation (Fig. 2), e.g. to eliminate vibrations transmitted from the engine to the locomotive, from a locomotive to wagons - this ensures better driving comfort for passengers, and also improves the lifetime of individual substructure system components - the vehicle. The technical condition of this system has an impact on the dynamic behavior of the vehicle on the track, its stability, and thus the safety and level of vibrations transmitted from the vehicle to and from the vehicle, through the ground into the surrounding environment.

Using the generalized Heaviside operator [9] form

$$
p_{q}=\frac{i d}{\int_{o}^{t}}
$$

and dependence

$$
\frac{d^{n}}{d t^{n}}=p_{q}^{n},
$$

in the case of homogeneous initial conditions for the differential model of the $R, L, C$ circuit, the relationship between the system response and its override (control) can be assigned according to [9] using generalized $\mathrm{G}$ transfer function $\left(G\left(p_{q}\right)\right.$, which in this case is given by the formula

because

$$
G\left(p_{q}\right)=\frac{p_{q}}{L p_{q}^{2}+R p_{q}+\frac{1}{C}}=\frac{1}{L p_{q}+R+\frac{1}{C p_{q}}}
$$

$\left(L p_{q}^{2}+R p_{q}+\frac{1}{C}\right) I=p_{q} E$.

The operator function is specified here 


$$
Z\left(p_{q}\right)=\frac{1}{G\left(p_{q}\right)}=L p_{q}+R+\frac{1}{C p_{q}}
$$

is the impedance of the $R, L, C$ system. Due to the dependence (1) by analogy, the concept is transferred to vibrating mechanical systems $m, k, r$ and is a mechanical impedance of the form

with respect to the speed of displacement or form

$$
Z\left(p_{q}\right)=m p_{q}+r+\frac{k}{p_{q}}
$$

$$
Z\left(p_{q}\right)=m p_{q}^{2}+r p_{q}+k
$$

with respect to displacement, and is a generalization of the elastic force factor.

These basic models have a very important practical meaning because many complex models describing vibrations in real transport systems arise from the basic analog ones (as in (1)) by their parallel or serial connection.

An important factor affecting the minimization of the level of mechanical vibrations transmitted from the locomotive to the wagons is their appropriate limiting or eliminating in specific frequency ranges through draw-back devices that play the role of vibration eliminators (Fig. 2) or mechanical filters. These devices are modeled by analogous electric filters: low-pass, high-pass, band-pass, middle-evaporation, i.e. $R, L, C$ systems.

Linearized vehicle motion system, treated as a generalized dynamic system [9], in which the acceleration of wheel centers of wheelsets was adopted as the input signal, as a result of kinematic extortions of wheels from the unevenness of the track is the form $\dot{x}=A x+B u$,

where: $\mathbf{x}$ is a state vector, $\mathbf{A}$ is a process or system matrix containing inertia, damping and stiffness, $\mathbf{u}$ is an excitation vector, $\mathbf{B}$ is an extortion matrix.

On the basis of (2) and (3) and on the basis of the definition of the generalized transfer function [3] we have

$\boldsymbol{G}\left(\boldsymbol{p}_{q}\right)=\left(\boldsymbol{p}_{q} I-\boldsymbol{A}\right)^{-1} \boldsymbol{B}$, an operator transfer matrix, from which we get a spectral transmittance matrix of the form $G(i \omega)=(i \omega I-A)^{-1} B, i^{2}=-1$, which is the characteristics of vibration filtration.

The frequency of excitations from the transmission system and the unevenness of the track at appropriate driving speeds may cause amplification of vibration amplitudes at frequencies close to the inherent frequencies of the system and, as a consequence, transmit vibrations through a cable mechanism, e.g. from a locomotive to wagons. A similar situation occurs when the train is braked using the selected braking mode [11] depending on the type of train driven by the locomotive. It is a matter of choosing such a braking mode so that the longitudinal and transverse vibrations of the train's entire composition resulting in the braking of the composition in extreme cases will be reduced.

In the case of electric locomotives supplied from the traction network, the cooperation of so-called collector (Figure 3) with traction network (with overhead contact line). One of such models (without dry friction) is a model composed of two connected masses: the equivalent mass $\mathrm{m} 1$ of the overhead contact line and equivalent mass $\mathrm{m} 2$ of the receiver, damping of the receiver, stiffness $k$ of the catenary subjected to forces: mechanical force $F_{1}$ lifting and aerodynamic force $F_{2}[8]$. Due to the fact that we are dealing here with the $R, L, C$ type oscillating system, on the basis of analogy (1) we get the ordinary differential equation of the second order form

$$
\left(m_{1}+m_{2}\right) \ddot{y}+r \dot{y}+k y=F_{1}+F_{2}
$$

describing vibrations of the mass system of the collector - the traction network. This system can, as previously mentioned, assign operator transmittance and mechanical impedances [5]. 


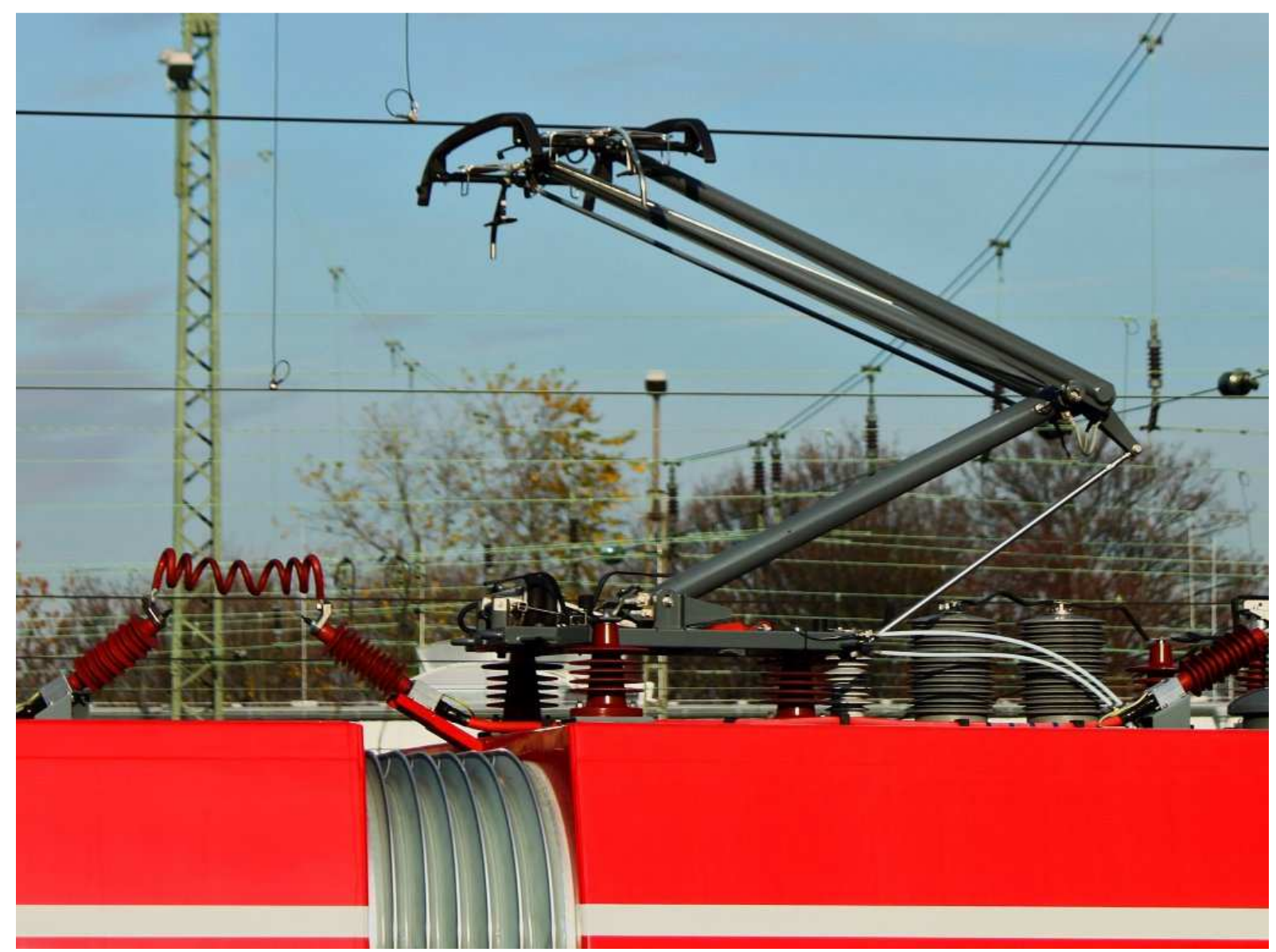

3. The current collector from the traction network (pic. Mario Schürholz www.bahnbilder.de)

Vibrations generated by land transport equipment (vehicles, pipelines, tunnels, bridges, airport plates, etc.) are transferred to other objects directly or indirectly through the ground, even over very long distances, causing negative effects. The best example of how long-distance vibration is transmitted through the earth is the following case. At the end of May 2017 in Koszalin, on one of the housing estates, residents of several skyscrapers felt vibrations in their apartments. About a thousand people were evacuated. Research with the use of seismographs and conducted experiments (a series of test microbuses) confirmed the supposition that the reason for this situation was the method of explosions used to reinforce the subsoil in the area of Sianów, used on the construction of the S6 express road. It is worth adding that the mentioned method was carried out in a place about three kilometers from the buildings in which its negative effects were observed. From this, it follows how important from a practical point of view is the problem of propagation of vibrations in the ground and their reduction or elimination.

Analyzing the constitutive equations based on Navier's equations supplemented by the elements responsible for the inertia forces for the elastic half-space $[6,13]$ we obtain differential equations for longitudinal and transverse waves $u$. In each of these cases, they are partial differential equations [1] with the same structure and in the case of a one-dimensional case can be presented in the form

$$
\frac{\partial^{2} u}{\partial t^{2}}=a^{2} \frac{\partial^{2} u}{\partial x^{2}}
$$

where the positive parameter a characterizes the half-space in relation to the type of vibration being analyzed (longitudinal and transverse). 
We are looking for the answer of the dynamic system with distributed parameters (4) in the set $D=\{(x, t): x \in R, t>0\}$ under initial conditions:

$$
\begin{aligned}
& u(x, 0)=\phi(x) \\
& u_{t}(x, 0)=\psi(x)
\end{aligned}
$$

Where functions $\phi(x), \psi(\mathrm{x})$ are functions with continuous derivatives respectively of the second and first order on a straight line $R$ [4].

To a dynamic system (4) we can join function $f(x, t)$ characterizing the source of vibration generating a heterogeneous differential equation. Using [9], its solution is easily presented in the following form of the operator

$$
u(x, t)=\frac{p_{q}^{2} \varphi+p_{q} \psi}{p_{q}^{2}-a^{2} \frac{\partial^{2}}{\partial x^{2}}}+\frac{f}{p_{q}^{2}-a^{2} \frac{\partial^{2}}{\partial x^{2}}} .
$$

Analysis of the formula (5) shows that for the one-dimensional model, the vibrations propagate towards the straight lines

$$
x+a t=0 \quad i \quad x-a t=0
$$

with the speed a in "right" and in "left". This is clearly visible in Figure 4, where simplification was adopted $\mathrm{a}=1$ i $\phi(x)=\frac{1}{4}-x^{2}$ for $|x|<\frac{1}{2}$ and 0 and others $\mathrm{x}, \psi(x)$ is a square pulse signal with a height $\frac{1}{4}$ specified in the range $<-\frac{1}{2}, \frac{1}{2}>, \mathrm{f}(\mathrm{x}, \mathrm{t})=0$.

network (pic. Mario Schürholz www.bahnbilder.de) 

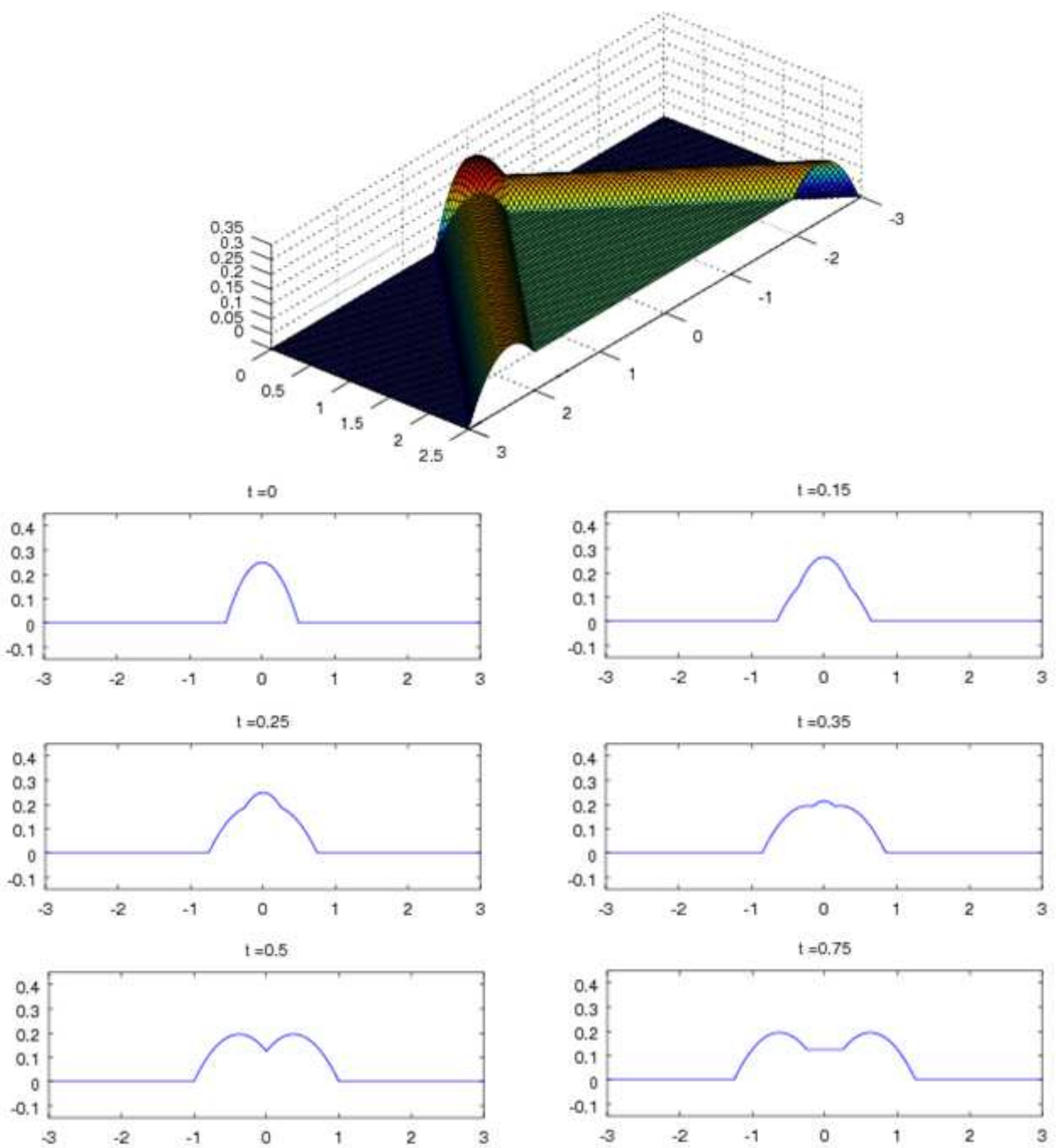

4. The propagation of vibrations at a given $\phi(x)$ and $\psi(x)$ for $a=1$ and their shape for set moments $t$

For modeling the behavior (propagation) of contact wire oscillations [8] by analogy, similarly as before, the dynamic system (4) is used, in which $a^{2}=\frac{F_{0}}{\varrho}$, where $F_{0}$ it is the netting force (about $10 \mathrm{kN}$ ), while $\varrho$ is the linear density of the network depending on the material of the contact wire. They are vibrations $u(x, t)$ in a contact wire in a onedimensional model, propagating at speed $a=\sqrt{\frac{F_{0}}{\varrho}}$ (Fig. 4). Mentioned equation (4) can be extended by the impact of the collector and then, as before, the member $f(x, t)$ leading to the non-free system will appear. 


\section{Summary}

Many important models used in practice are worth creating based on the analogy between the phenomena described. Models of complex systems are created by a chain or parallel connection of basic systems. Thanks to analogies, concepts functioning in one domain of knowledge can be transferred to another with a good result. Analog modeling works well in practice, especially for qualitative analysis of vibration of engineering problems. Analogue models allow on the basis of one, decide for example about the technical stability of the other and vice versa.By identifying the model, you can go to the quantitative analysis of the examined problems.

\section{Source materials}

[1] Bicadze A. W., Równania fizyki matematycznej, PWN, 1984

[2] Chan T.H.T., Yu L., Tam H.Y., Ni Y.Q., Liu S.Y., Chung W.H., Cheng L.K., Fiber Bragg grating sensors for structural health monitoring of Tsing Ma bridge, Background and experimental observation, Engineering Structures, 28, 2006

[3] Edwards R., Functional analysis. Theory and applications, New York, 1965

[4] Evans L. C., Partial Differential Equations, American Mathematical Society, 1998

[5] Feynman R. P., Leighton R. B., Sands M., Feynmana wykłady z fizyki, PWN, 2001

[6] Gryczmański M., Wprowadzenie do opisu sprężysto - plastycznych modeli gruntów, Wydawnictwo PAN, Studia z zakresu inżynierii nr 40, Warszawa 1995

[7] Hong-Nan Li, Dong-Sheng Li, Gang-Bing Song, Recent applications of fiber optic sensors to health monitoring in civil engineering, Engineering Structures, 26, 2004

[8] Judek S., Karwowski K., Mizan M., Wilk A., Modelowanie współpracy odbieraka prądu z siecią trakcyjną, Przegląd Elektrotechniczny, 11, 2015, 248 - 253

[9] Mieloszyk E., Nieklasyczny rachunek operatorów w zastosowaniu do uogólnionych układów dynamicznych. Wydawnictwo PAN, Gdańsk 2008

[10] Milewska A., A certain solution of non-linear differential problem with application to selected geotechnical problems, Archives of Civil Engineering, LVIII, 2.

[11] Simens A. G., Instrukcja obsługi czterosystemowej lokomotywy wysokiej mocy serii 189.

[12] Tihonow A. N., Samarski A. A., Równania fizyki matematycznej, PWN, 1963

[13] Verruijt A., An Introduction to Soil Dynamics, Springer, 2010

[14] Zwillinger D., Handbook of Differential Equations, Academic Press, 1984 